\title{
Algo sobre la identificación de delincuentes
}

\author{
Por LUIS COBIAN C., \\ del $4^{9}$ Año de Derecho.
}

Cuando la Ley del Talión había pasado ya a formar parte de la historia de la represión, se presenta para los encargados de administrar justicia un problema, y este es: ¿cómo saber si el acusado ya lo había sido en otra ocasión - es decir, si era reincidente-- c si ai contrario por primera vez se presentaba a rendir cuentas ante los magistrados del fuero penal?

A pesar de la gran importancia del "asunto", éste, no fué resuelto en forma total, es decir estrictamente científica, sino a comienzos de nuestro siglo, como lo veremos a continuación.

De manera muy rápida echaremos una mirada a la forma de la identificación en el antiguo derecho, empleando tal término sólo para comprender dentro de él la materia de este trabajo antes de la casi universalización de la Dactiloscopia, sistema grandioso que hoy emplea la Policía Científica en la gran mayoría de los países en su lucha contra la delincuencia.

Antes de entrar en materia, veremos lo que se entiende por IDENTIFICACION y nos bastará con citar la definición que dá Legrand du Saulle en su importante tratado "Médecine Légale", publicado en 1886. Dice así: "la identidad es la determinación de la individualidad de una persona", y agrega, "los fines que se relacionan con la identidad tienen por objeto determinar si un individuo es realmente el que pretende ser, y si es el que la justicia presume reconocer; el hallazgo de los caracteres que permiten reconocer a una persona que la distingue de otra, será evidentemente la base del sistema de identificación".

Se lee en las antiguas leyes recopiladas de España cómo se identificaba a un criminal: la " $L$ " o marca judicial a hierro candente, que se colocaba en el hombro derecho del que había trasgredido la ley; antes la "O" en Grecia, la Flor de Lis en Francia y las llaves entrelazadas -emblema inmemorial del escudo pontificio - nos bastan para saber de que modo en una primera época se reconocía a un delincuente. Como vemos, era un procedimiento sencillo: bastaba con descubrir el hombro de un sospechoso para saber si era o no un transgresor de la 
ley. Tal modo de identificación denigra a la persona humana, aunque si bien es cierto - por una parte-- que no sólo a la policía científica le estaba reservado el privilegio de poder reconocerlo, tal como sucede hoy en día, sino que al contrario se encontraba al alcance de todos. En efecto, las marcas estaban escritas en lenguaje universal; de tal manera podía haber mayor defensa contra los delincuentes. Mas contemplada la "marca" desde otro ángulo tenemos que admitir que su crueldad e ignominia llevaban a convertir al marcado en un gran peligro social, ya que sobre él pesaba tal estigma.

La marca fué una institución que pronto cayó en desuso, contribuyendo a ello en forma principalísima una pluma que conquistó al mundo docto de su época y que va a señalar una nueva etapa en la evolución del Derecho Penal. Me refiero al noble italiano César Bonesana, Marqués de Beccaria, quien en su obra "Dei delitti e delle pene", pequeña pero gran obra, publicada en 1764 en forma anónima, hace ver al mundo la crueldad de las penas que entonces se aplicaban y al hacerlo toca a la "marca", que sin aplicarse como tal, lo era.

El derecho moderno se ha negado en forma terminante y unánime a que la marca aparezca bajo forma alguna, ni siquiera atenuada, por cuya razón no tuvo acogida el sistema patrocinado por la escuela de Locard, (notable jefe del laboratorio de medicina legal de Lyon) quien quiso substituír la antigua marca por un método de "tatuaje judicial", semejante a un alfabeto Morse -ya que constaba de puntos y rayas-. Este "tatuaje" era hecho en los espacios interdigitales, aunque no fácilmente visibles, y debían revelar a la justicia las características de peligrosidad social del sujeto. Vanamente se ha intentado también el poner en práctica un sistema de inyecciones subcutáneas de parafina para que formen bajo la piel un sistema de signos que permitan la fácil identificación de los reos.

En la primera mitad del siglo XIX se organiza por primera vez, y en Francia, el "casillero judicial" ideado por Bonneville de Marsangy, el que consistia en ordenar en casillas-tarjetas, debiendo figurar en ellas alfabéticamente los nombres de los criminales y su lugar de nacimiento. Debiendo ser estos datos proporcionados por los detenidos, tenemos que concluir expresando que este sistema es totalmente ineficaz dada la facilidad de poder alterar la verdad en el momento de la declaración. Tampoco tuvo vida larga el método de las "cartillas biográficas", impuestas obligatoriamente por las autoridades policiales francesas a đeterminada clase de personas sospechosas: mujeres públicas, ciertas profesiones, etc.. Las reseñas que contenían estas cartillas eran también totalmente ineficaces y esto era debido a su extrema vaguedad. Tales reseñas estaban constituídas principalmente por la estatura, color de los ojos, tamaño de la boca.

La identificación de los malhechores dá un paso enorme con el descubrimiento de la fotografía. Obvio es decir que los gabinetes de identificación la emplearon añadiéndola a las "cartillas biográficas". El procedimiento de la identificación de reincidentes basado en la fotografía fué utilizado durante varios años, siendo éste un método al que no se le puede negar un gran valor, pero que expone a numerosos errores y bástenos por ejemplo el "paneau" que, en los últimos meses del año pasado, publicó "La Prensa" de Lima el que consistía de doce retratos, 
los que pareciendo ser de distintas personas todas ellas pertenecian al ex-dictador de Alemania, Adolfo Hitler. Por el error a que puede pues conducirnos la fotografía fué necesario idear procedimientos precisos y no confiar en la impresión, con frecuencia inexacta, que resulta del examen de su conjunto.

En la última década del siglo XIX, el doctor Alfonso Bertillón idé un sistema antropométrico, el que fué bautizado por sus contemporáneos con el nombre de "bertillonage", inaugurando en París, a fines del año 1882, la primera oficina antropométrica el Prefecto de Policía. Tres años más tarde, el gobierno se decidió a recomendar la adopción del sistema y sólo en 1888 recibió su consagración definitiva.

El "bertillonage", "signalement anthropométrique et descriptif", por L. Thoinot, fué recibido con gran entusiasmo y tuvo gran resonancia. Aparece en una época en la que el reconocimiento de los reincidentes se hacía según el sexo, la edad, particularidades anatómicas y patológicas. Está basado en una reseña descriptiva - tan completa como sea posible - de los caracteres antropométricos y crométricos de cada individuo tomados a partir de la fijeza del esqueleto, es decir en la adolescencia; además las señas particulares del sujeto. Es condición sine qua non, dice Bertillón, que los caracteres antropométricos sean tomados de una manera rigurosamente uniforme y precisa.

Estos caracteres fueron sistematizados por el servicio de identidad de París, creando la Ficha Antropométrica. Tiene este método la ventaja de permitir una clasificación fácil de los delincuentes. Todo individuo que es arrestado posee una de estas fichas, las que constan de un anverso y un reverso; se coloca en el primero las medidas antropometricas y los caracteres cromáticos, así como el retrato tanto de frente como de perfil, para terminar con las impresiones digitales de la mano derecha comenzando con el pulgar. El reverso de la ficha está destinado al nombre, apellido, apodos o sobre nombres, fecha de nacimiento, profesión y por último, el motivo de la detención del delincuente. Además dentro de un cuadro especial figura la mencion -en un lenguaje convencional- de las señas particulares (nevus, tatuajes) y cicatrices así como las impresiones digitales de la mano izquierda, tomándose primeramente la impresión del pulgar.

Los caracteres cromáticos señalados en la ficha parisiense -color de la piel, del iris, de los caballos, de la barba - ya no son como aquellas conceptuaciones vagas de las primeras cartillas, sino con referencias muy precisas a determinadas escalas de color puestas en uso, generalmente la escala de Broca. Las fotografías que en ellas se colocan están reducidas en $1 / 7$; en un principio la reducción fué de 1/5. Los caracteres antropométricos que integran la ficha son los siguientes: cabeza, su longitud, diámetro bixigomático y anchura; longitud del pie izquierdo, longitud del auricular izquierdo, longitud de la oreja derecha, longitud del codo izquierdo, completándose con la talla, brazo y busto. Las mediciones de tales partes del cuerpo se practicaban con aparatos muy exactos, tales como: toesas, compases de espesor y escuadras, debiendo estar el sujeto sometido a la operación en idéntica posición durante toda ella. Hay una tabla que la podemos llamar del error 
permitido, ya que en ella se encuentran las cifras que indican el error, que se permite en cada una de estas partes medidas.

La clasificación de las Fichas Antropométricas se realiza dividiendo e estas en tres grupos según la longitud de la cabeza, de la manera siguiente: pequeña (hasta 18,3), mediana $(18,3$ á 18,9) y grande (más de 18,9 ); a su vez estos tres grupos se subdividen en otros tres subgrupos según la anchura de la cabeza. En esta forma la búsqueda de determinada ficha no exige, con una clasificación tan metódica, sino algunos minutos para encontrar al sujeto examinado, si ya éste ha pasado por manos de la justicia.

Como se vé, este sistema es excelente para obtener fichas de clasificación fácil, todas diferentes entre sí, mas no lo suficiente para la identificación, ya que los errores de medición conducen a establecer para un reincidente una ficha que no es nunca idéntica sino que tan sólo es semejante, a pesar de que la ficha parisiense estaba integrada por las impresiones digitales -Bertillón no hizo caso omiso de ellaspero no como fundamento del sistema, de allí que no se hiciese la clasificación de las fichas sobre tales impresiones, al contrario de lo que sucede con la dactiloscopia. $Y$ he aquí su gran ventaja.

Podemos formular contra el "bertillonage" las siguientes objeciones:

1) Tiene sólo en cuenta a individuos que han alcanzado el desarrollo completo.

2) El método está basado sobre el hecho de que el desarrollo del ser alcanza a los 22 años. Mas no todos los antropólogos están de acuerdo con señalar tal edad; unos señalan los $25 \mathrm{y}$ hay quienes afirman que la fijeza del esqueleto sólo se alcanza a los 40.

3) Admitido como está el punto número uno, escapan al control del "bertillonage" todos los delincuentes precoces y reincidentes enseguida.

4) Todas las partes del esqueleto que se toman en cuenta para las mediciones y en forma especial la estatura, se modifican con la vejez.

5) Dada la idéntica posición que el individuo examinado debe observar durante toda la operación puede éste fácilmente cambiarla y modificar así el resultado.

El más ingenioso de los descubrimientos de Bertillón lo constituye el llamado "Portrait Parlé" - retrato hablado- que consiste en una descripción metódica en forma breve y minuciosa, usando un lenguaje convencional, de las facciones humanas que sustituye ventajosamente a la vaguedad e impresición de las antiguas señas personales, a las cuales ya nos hemos referido al ocuparnos de las "cartillas biográficas". Su importancia radica en que queriendo identificar a un sujeto, por ejemplo en una aglomeración, haciendo uso de este método se hace más fácilmente posible su localización. No es posible señalar todas las particularidades de la fisonomía que pueden constituír el retrato hablado: nos limitaremos a señalar las principales que sirven de base para su constitución.

Tomaremos, en primer lugar, la nariz, la que si la observamos de perfil veremos que en ciertos individuos el dorso tiene un arco cóncavo, en otros es convexo existiendo perfiles rectilíneos. Con el fin de facilitar 
su empleo se usan las siguientes abreviaturas: "CAV" para la primera forma, "VEX" para las de forma convexa $y$ " $R$ " para las últimas $y$ como entre una y otra forma existen todas las transiciones se forma una verdadera gama; así para indicar una nariz muy cóncava se coloca una raya debajo de la abreviatura que le corresponde "CAV"; si esta misma abreviatura se encuentra cerrada dentro de un paréntesis significará muy poco cóncava (CAV), si encontramos la abreviatura correspondiente a una nariz convexa con alguno de los signos que acabamos de indicar quiere decir o significar lo mismo; de tal manera que un agente de policía dejará pasar a todos los individuos de nariz rectilínea o convexa si el que busca tiene nariz cóncava.

Otro de los rasgos que principalmente se toma en cuenta para la constitución del retrato es el lóbulo de la oreja derecha el que unas veces se inserta en descenso o en ángulo recto. llamándose entonces descendente o en escuadra usando para tal forma la abreviatura "DEQ"; otra veces por el contrario está en ascenso usando para su designación la abreviatura anterior anteponiéndose la negación nó - "NO DEQ"De la oreja también se toma en cuenta el pliegue inferior, el que visto de delante hacia atrás o viceversa puede tener una forma cóncava o convexa hacia el exterior designándoles respectivamente con las abreviaciones "CAR" y "VEX". La foseta navicular, la eminencia más o menos pronunciada del antitrago junto con las anotaciones de los signos particulares más raros y por consiguiente más característicos deducidos del estudio de las arrugas, de la forma general de la cara, del color del iris completan el "Portrait Parlé". Como crítica quisiera escribir unas líneas: el retrato hablado sólo tiene eficacia para los que han pasado por el gabinete de la policía cientílica, pues si al detener al presunto delincuente, ya que sus datos coinciden con los consignados en el "retrato", resulta que la clasificación dactiloscópica del pulgar derecho fuese delta y la del detenido bidelta, el "Portrait Parlé" realizaría una notable plancha.

Para terminar con Bertillón hay que escribir algo sobre los "albumes" de los que él también es creador. Bertillón, para facilitar las investigaciones policiales ha agrupado en "albumes" los retratos hablados de los sujetos contra los que se hayan expedido mandamienio de prisión así como de todos los expulsados de París. Tales albumes son conocidos con el nombre DEV, formado por la abreviación de las letras con que se designan algunas de las particularidades fisonómicas integrantes del "retrato". Se encuentran divididos en tres partes, en la parte superior se hallan colocadas las particularidades de la narlz, mientras que en las partes laterales están designadas por los rasgos característicos de la oreja. Con tal sistema es fácil la localización de un fichado dentro de estos albumes.

Bien, de manera somera hemos ido recorriendo las diversas maneras de identificación, desde la marca hasta los sistemas ideados por el Dr. Bertillón y a través de este recorrido hecho a grosso modo se puede apreciar que el sistema de la identificación ha ido perfeccionándose poco a poco, pero no lo suficiente como para que los estudiosos de esta materia no siguiesen investigando hasta dar con un mejor método de identificación. La ola creciente de la criminalidad les imponía el 
deber de multiplicar sus medios de investigación para descubrir y reconocer con prontitud y de manera certera a los reincidentes peligrosos, y así llegamos a fines del siglo XIX.

Se vió por fín que cada uno de los seres humanos desde los primeros meses de la vida intrauterina - perfectamente definidos a los seis meses de la vida fetal - hasta la descomposición de los tejidos por la muerte, vienen al mundo dotados de un sistema individual que se encuentra particularmente entre la faz palmar de los falanges extremos, los que están surcados de pequeñas líneas representando dibujos más o menos complejos; en el intervalo de estas líneas vienen a abrirse los conductos excretores y sudoríparos. Esto constituye lo que conocemos con el nombre de huellas digitales, las que se producen por la aplicación del dedo entintado o nó.

Los precedentes de este método de identificación son muy remotos y no exageramos si además decimos que fueron más exóticos; tan remotos son que algunos investigadores del arte aupestre y de la prehistoria quieren encontrar las primeras manifestaciones de la dactiloscopia en el interior de las cavernas del cuaternario $\mathrm{y}$ en determinados monumentos megalíticos; hay una pequeña isla (Gavr' Inis) en Francia, donde existe una gran cantidad de piedrafitas donde se puede observar una estilización de los tipas fundamentales de dactilogramas. Investigaciones realizadas por los estudiosos, que querían encontrar el origen de este método, han llegado a la conclusión de que muchos siglos antes de su aplicación en el occidente, ya en el lejano oriente los japoneses lo conocían. Al respecto hay un estudio que podemos decir exhaustivo del nipón Humugani Manikota quien demuestra que las huellas dactiloscópicas se conocían en su país desde el siglo VI de la Era Cristiana, confirmado esto por las investigaciones posteriores realizadas por europeos. Hay autores que atribuyen a las huellas a que se refiere Manikota nada más que ritos simbólicos. Sin entrar en discusión al respecto diremos que lo que sí es verdaderamente cierto es que en los últimos años del siglo XIX, los viajeros europeos y de manera principal los ingleses, hallaron por primera vez la dactiloscopia como método de identificación en el Japón y lo transportaron a sus respectivas metrópolis.

Debemos a Inglaterra el poner en circulación este sistema, aplicándolo por primera vez en la India, usándolo en los recibos de los obreros analfabetos, en reemplazo de la señal de la cruz usual en Europa, pero ya con un contacto tal de los dedos que permitiera después la identificación de los sujetos por confrontación de sus huellas digitales. Uno de los primeros métodos de identificación dactiloscópica, todavía primitivo y harto complicado se debe a Galton, gran antropólogo creador de la Eugénica, quien en 1891 publica su "Philosophical Trasactions" en el que se ocupa de este método; tras Galton siguen otros muchos. Bástenos con citar a Feré, Testut, etc., y este sistema comienza a ponerse en uso, desplazando cada vez más al "bertillonage", debiendo, y esto hay que admitirlo sin lugar a dudas, su perfeccionamiento y casi universalización a Juan Vucetich, croata naturalizado argentino, quien en 1913 recorre el mundo buscando los orígenes de la dactiloscopia. Es él que en Buenos Aires crea el primer laboratorio dactiloscópico. Vucetich estudiando las finas estructuras papilares de las yemas de los de- 
dos, viene a reunirlas sólo en cuatro grupos dándoles los siguientes nombres: "arco" donde las crestas papilares pasan de un lado a otro del pulpejo sin dejar ninguna presilla; segundo la "presilla interna" donde las crestas papilares saliendo del lado interno, se encurvan para volver al mismo lado; en el lado externo del pulpejo se encuentra un triángulo al nivel del cual se forma otro constituído por crestas que pasan directamente de un lado a otro sin incurvarse; tenemos después la "presilla externa" que difiere de la anterior en la dirección de la presilla; siendo el último grupo llamado "verticillo" en el cual las crestas papilares forman un circuito completo alrededor de un centro.

El doctor Federico Oloriz, maestro de la anatomía y de la antropología española, señala también cuatro grupos que son en realidad los mismos cuatro tipos que acabamos de indicar, señalándolos con los nombres de origen griego: "adelto", "dextro", "siniestrodeltos" y "bideltos" respectivamente.

Obtenida la impresión, es fácil expresarla por medio de un número quebrado, cuyo numerador indica los tipos a que corresponden las huellas de cada uno de los cinco dedos de la mano derecha, y el denominador los dedos de la mano izquierda. Estas papeletas se pueden ordenar y clasificar como se ordenan las palabras de un diccionario, logrando en pocos minutos precisar si las huellas de un criminal se hallan archivadas. Pero no solamente en esto reside la importancia de la dactiloscopia, sino que además permite otra operación no menos importante que la anterior y esta es: descubrir a un delincuente.

Como quiera que el hombre en la realización de sus actos ha de servirse de la mano, y como quiere que donde la mano se apoya deje una huella visible o invisible -puede decirse que el hombre sella, firma todo cuanto toca-, en orden al delito, deja también su propia firma en el lugar donde lo cometió, y que ha de denunciarle y de hacerle fácilmente recognoscible. Ni siquiera es necesaria una huella completa, perfecta, ya que la ciencia está tan avanzada, que le permite descubrir la personalidad del delincuente en una huella borrosa, a veces dejada sobre un vidrio o sobre una superficie metálica o bien sobre una sustancia blanda, una bujía, en una palabra, sobre cualquiera de todas esas cosas tan usuales y tan domésticas que de ordinario aparecen en el lugar del crimen. Ya de nada le sirve al malhechor poner en práctica el antes muy usado método de rasparse los relieves de las crestas papilares o el actual del uso de guantes, ya que la reacción del delincuente va siempre acompañada de una cierta hipersecreción de sudor que, infiltrándose a través de los poros de los tejidos, permiten impresiones susceptibles de ser identificadas. Poroscopia se denomina a la ciencia que se ocupa de reconstruir las huellas digitales que quedan impregnadas en los objetos tocados con los guantes.

Como se ha dicho ya la dactiloscopia rápidamente se extendió en el mundo y esto se debe a las siguientes razones, que equivalen a enumerar las ventajas de tal sistema:

1) El resultado de las observaciones que han hecho los estudiosos de esta materia - tanto antiguos como modernos- han confirmado que el dibujo digital es perceptible desde los primeros meses de la vida intrauterina alcanzando su completo desarrollo hacia el sexto mes en el 
que crece simultáneamente con el resto del organismo y se conserva inalterable en su forma y disposiciones originarias durante toda la vida.

2) Las líneas papilares responden a disposiciones típicas que hacen único el dibujo, como es única la persona que las posee.

3) En este sistema no hay margen de tolerancia sin error posible; si se toma cien veces la impresión del pulgar de tal o cual persona, las cien veces será igual el resultado.

4) Este sistema se basa en un carácter que ni la edad ni los padecimientos físicos pueden modificar los dibujos papilares.

$\mathrm{Y}$ así hemos visto cuales son los méritos y la eficacia de la dactiloscopia. Aludo naturalmente a una dactiloscopia bien organizada, bien dirigida y sobre todo en ia cual se logren las huellas dactiloscópicas de una manera que pueda servir para la identificación por el método corriente de impregnar el dedo en cualquier tinta, volteándolo sin cuida do sobre el papel y dejar una huella borrosa que no sirve para las operaciones más elementales. Esta ciencia avanza a las aplicaciones civiles jurídicas más completas. La dactiloscopia en lo sucesivo ha de ser la base cierta y segura para la reconstrucción de un verdadero registro del estado civil. Ya en algunos países se ha puesto en práctica con resultados muy satisfactorios. 